a grain, and he was beginning to put on flesh. The emaciation had been excessive. My assistant unfortunately allowed himself to be persuaded at this moment to give him a small dose of heroin and in a few days he became quite unmanageable and developed a condition of semi-mania and agitation. When I was told this I stopped the heroin at once, allowing four grains of morphia, and after a fortnight's resistance, rectal injections being substituted and the patient professing to be entirely free from discomfort, the treatment was organised in a much severer manner. He had previously supposed himself to be getting cured voluntarily. After a week it was discovered that he had all the time managed to deceive. Each time the rectal supply of morphine was given he had slipped the cannula off the syringe and fixed it to a hypodermic needle previously inserted in the skin of the abdomen. When this was discovered the possibility of its repetition was guarded against, and the treatment was henceforth carried on without reference to his wishes or recriminations. In 10 days more the morphia was suppressed without his knowing it. He acknowledged that he had had no feeling of craving;, but notwithstanding this he felt an irresistible impulse to take any drug that might be left at his hand. $A$ fortnight after the last morphia he recognised that the mercurial treatment which he had been persuaded at last to adopt had been of the greatest benefit. All his sores and abscesses were cleaning and healing; but here, again, to make up for lost time he would treat himself in his own way by excessive doses. He declared that the protoiodide of mercury gave him feelings of euphoria.

The patient in this case is certain to relapse, for although he admits that he has no craving his one wish is to find a pretext for returning to morphia. He is in the same state of mind as the greater number of those who have been cured by compulsion in special houses, and is an example of the hopelessness of a cure being permanent when so conducted. 9

CASE 8.-An American lady, 28 years of age, voluntarily submitted to be treated in order to please her protector; but when the morphine was getting low, although she did not ask for more, she manifested every hysterical symptom imaginable calculated to force $m y$ hand. It began by hvsterical vomiting and anorexia. This condition not having been considered by me as a sufficient reason for moderating the treatment, a consultation was asked for with Professor Raymond who endorsed my statement that it should be continued as before. As the progression continued the intention of returning to morphia was admitted, the bitterest complaints were made as to craving, and symptoms of extreme hysterical agitation developed. Fortunately, all her servants recognised that it was their interest to prevent her relapsing and combined to coöperate in the treatment; and the different merlical men whom she insisted on seeing, with one exception, declared that the treatment should be carried through. 'To comteract this rather strange exception I fortified myself by the coóperation of Professor Labadie-Lagrave and henceforth no further interference was allowed and the progression was continued mercilessly. It is not that there was any real suffering, but a refusal to give a supplement of morphia to relieve the terrible craving that was simulated would throw my patient into the most violent excitement. On one occasion, in her anger at not being able to have her own way, she very nearly managed to drown herself in a large American bath. After being received with speechless indignation when it was not with tearful reproaches, I could always manage to excite her interest, and 10 minutes later she would be gaily talking about some absorbing inatter, toilette, jewellery, or the races, or, perhaps, the progress of my other morphia cases, in which she took great interest. She recommended to me, for them, "the greatest firmness." "The complaints of "craving" would be repeated at first from time to time; but after she had forgotten them two hours would often elapse without its being remembered. The reduction was carried out under these conditions, imaginary extra doses being sometimes accorded, and the morphia was given up as per programme. Inlike the next case to be related, when she recognised that she was cured she was most grateful.

CASE 9.-A lady, aged 50 years, but looking 70 years of

${ }_{9}^{9} \mathrm{My}$ previsions have been realised since writing this paper, the patient having relapsed to cocaine, not morphine-that is, not on acrou't of a craving, but in order to re-taste the regretted stimulation. age, was sent to me by Dr. Bérillon. She was covered with abscesses, she had scarcely a tooth left in her head, the urine was slightily albuminous, and she was in so great a state of prostration that her ordinary medical attendant in the suburbs did not expect her to live and looked upon her removal to Paris as most dangerous. Before coming under my care the morphia had been kept within bounds to a certain extent by her medical man and she was then only taking 12 grains. In this case the same thing occurred exactly as in the previons one. When the last hypodermic syringes were reached the patient, who was resolved to compel me to return to larger doses, manifested all kinds of hysterical symptoms and claimed to be suffering from the most acute craving. She had begged me on her knees not to delay the commencement of her treatment at first, when alarmed about her condition, for there had been some question of a delay for a few days. But as occurs in these hysterical cases when the morphia was reduced to the period of rectal injections, in which period it is impossible to feel craving, she became loath to give up the syringe and wanted. as a fact, not to renounce all treatment, but to order the progression herself with me to countersign it. She had already been treated by dozens of other medical men who had been compelled either to look on or to throw up the case and she did not intend to allow herself to be constrained by me any longer than it suited her inclination. Supported. however, by her husband, she really took what had been arranged, thinking all the time that she was working her own sweet will. She had been having no morphine whatever for three weeks before she had any idea that she was near the end. Here the strange perversity of the hysterical temperament was fully shown. For tired at last of carrying on a comedy of a scene each night before $I$ would allow myself to give the (imaginary) extra morphine, I informed her one evening that she had taken none for three weeks and that I would not lend myself to this nonsense any longer. Instead of being pleased she became simply enraged, and, having recovered her health, persuaded her husband to give me mv congé. A few days later she was again taking large doses of morphia, and six weeks after she was found dead in her bed from an overdose of chloral.

There are two interesting points in this case : the first is that notwithstanding her protests of craving when she was aware of what she was taking, she was cured by my plan without discomfort; the second is the fact that in the morphia habit, however bad the phvsical condition may be, recovery is possible if the morphine is given up. Paris.

\section{PASTEURISATION OF INFECTED MILK.}

\section{By E. SYDNEY ST. B. SLADEN, M.D. CaNtab.,} JOHY LUCAS WALKER STCDEXT.

THE danger of using milk containing micro-organisms that cause scarlet fever, typhoid fever, diphtheria, and consumption is diminished by heating it to $80^{\circ} \mathrm{C}$, and keeping it at that temperature for 10 minutes. If the milk be heated to $85^{\circ} \mathrm{C}$. all such danger appears to be removed. In order to obtain exact information on this point I have collected the statistics contained in the following table in which are given the temperature and time required to bring about the death of, or to inhibit the action of, the tubercle bacillus. This temperature of $85^{\circ} \mathrm{C}$. is higher than is required to kill the micro-organisms of scarlet fever, typhoid fever, and diphtheria.

The first column gives temperatures rising by five degrees from $50^{\circ}$ to $90^{\circ} \mathrm{C}$. The seconà, third, fourth, and fifth columns give a sunmary of the results arrived at $k y$ $G$. Sims Woodhead ${ }^{1}$ in his report to the Royal Commission on Tuberculosis. The sixth column gives the opinions of various workers on this point.

The danger of using milk yielded by cows that have not passed the tuberculin test is without doubt a real danger. esprcially in the case of infants, young children, delicate people, and all those who have to be fed on a milk dift.

1 1. Report of the Roval Commission appointed to inquire into the Effect of Food derived from Tuberculous Animals, 1895, Part I., p. 19, 2. Appendix to the ahove report, pp. 145 to 179 . 1 and 2 refer to exper:2. Appendix to the above
ments made with milk. 
Table showing the Temperature and Time required to Bring about the Death of, or to Inhibit the ACtion OF, THE TUBERChe BachlLus.

\begin{tabular}{|c|c|c|c|c|c|}
\hline \multirow{2}{*}{ Temperature. } & \multirow{2}{*}{ Inoculation. } & \multicolumn{3}{|c|}{ Feering. } & \multirow{2}{*}{ Results of various experiments by- } \\
\hline & & Guinea-pigs, & Cats. & Pigs. & \\
\hline $50^{\circ} \mathrm{C}$ & 15 hours. & 5 hours. & 4 hours. & Not statod. & - \\
\hline $55^{\circ} \mathrm{C}$ & $7 \quad$, & $3 \quad$, & Not stated. & $,, \quad,$, & Forster and $\mathrm{C}$. de $\operatorname{Man},{ }^{*}$ four hours. \\
\hline $60^{\circ} \mathrm{C}$ & $8 \quad$, & 25 minutes. & 15 minutes. & Over the hour. & $\begin{array}{l}\text { Forster and } C \text {. de Man, one hour ; Bonhoff, } \uparrow \\
20 \text { minutes ; and Schroeder, } ₫ 15 \text { minutes. }\end{array}$ \\
\hline $65^{\circ} \mathrm{C}$ & $4 \quad$ & 2 hours. & 10 & Over 40 minutes. & $\begin{array}{l}\text { Forster and C. de Man, } 15 \text { minutes ; Forster, } \\
15 \text { minutes. }\end{array}$ \\
\hline $70^{\circ} \mathrm{C}$ & 45 minutes. & 20 minutes. & 30 &, 45 & $\begin{array}{l}\text { Forster and } \mathrm{C} \text {. de Man, } 10 \text { minutes ; Yersin, } \$ \\
10 \text { minutes ; Lidoux-Libard, } 9 \text { one minute. }\end{array}$ \\
\hline $75^{\circ} \mathrm{C}$ & 30 & 15 & Over 15 minutes. & , 15 & $\begin{array}{l}\text { Bitter, }{ }^{* *} 15 \text { minutes at } 75^{\circ} \mathrm{O} . ; \text { Forster and } \mathrm{C} \text {. } \\
\text { de Man, not stated }\end{array}$ \\
\hline $80^{\circ} \mathrm{C}$ & Simply heated to. & Simply heated to. & Simply heated to. & , 10 & $\begin{array}{l}\text { Forster and } \mathbf{C} \text {. de Man, five minutes; Copen- } \\
\text { hagen Milk-supply Company, } \dagger \dagger 30 \text { minutes. }\end{array}$ \\
\hline $85^{\circ} \mathrm{C}$ & $2 \frac{1}{2}$ minutes. & $"$ & Not stated. & Not stated. & $\begin{array}{l}\text { Forster and } \mathrm{C} \text {. de Man, not stated; Bang, } \\
\text { a few seconds. }\end{array}$ \\
\hline $90^{\circ} \mathrm{C}$ & Not stated. & $"$, & , & , & Forster and C. de Man, two minutes. \\
\hline
\end{tabular}

* Archiv fuir Hygiene, Band xviii., Heft 2. † Hygienische Rundschau, 1892, No. $23 .+$ Bulletin of the United States Bureau of Animal Industry, No.7, p. 75 . H Hygienische Rundschau, 1893 , No. 15. \$ Annales de l'Institut Pasteur, tome ii. p. 64. I Grancher and LidouxIibard: Archives de Médecine Expérimentale, \&c., 1892, vol. iv., p. 1. ** Zeitschrift für Hygiene, 1890, Band viii., p. 240. †† A. Steward MacGregor, British Vice-Consul, Copenhagen, 1890. It Nordiskt Mediciniskt Arkiv, 1899, N:O 22.

The danger of using milk that is not heated in any way is sometimes present where the water for washing the milkcans is contaminated with the typhoid bacillus, or where the milk is infected by the persons employed in the dairies who may be suffering or recovering from mild attacks of scarlet fever or diphtheria. With regard to the above wellauthenticated outbreaks have occurred The following evidence is conclusive as to the danger of using raw milk containing virulent tubercle bacilli. Dr. Harold Scurfield ${ }^{2}$ quotes Bang as follows: "In any large herd in which tuberculosis is rife one will be certain to find one cow the milk of which contains tubercle bacilli and which has tuberculosis of the udder." Out of 144 samples of milk coming from the Liverpool cowsheds, four, or 2.8 per cent, were found to contain the tubercle bacillus, but of 24 samples of milk "from the country" taken at the Liverpool railway stations, seven, or 29 per cent., were found to contain this bacillus. In some later experiments in Liverpool 12 out of 228 samples of town milk-i.e., 52 per cent.-were found to contain the bacillus. and nine out of 67 samples of country milk-i.e., $13 \cdot 4$ per cent. In Manchester 17 out of 93 samples of country milk were found to contain the tubercle bacillus. By permission of the farmers the city veterinary officer visited 16 farms from which the milk came, and on 14 of these farms he found at least one cow with tuberculosis of the ndder. Another example is cited by Nocard. ${ }^{3}$ The seventeen-year-old daughter of a medical practitioner in Geneva was in perfect health up to the end of 1892. No case of tuberculosis had occurred either on the father's or the mother's side of the family for several generations. In 1893 she began to waste away and the practitioner was able to assign no cause for the wasting; she died in a few months. A post-mortem examination showed that tuberculosis of the bowels was the cause of death. Inquiry showed that the family used to spend every Sunday at a small estate on the hills, and that this young girl was particularly fond of milk fresh from the cow. Four of the five cows on the estate when tested with tuberculin were found to react and were slaughtered. Two of the four had tuberculous disease of the udder. Dr. R. G. Freeman" writes as follows: "It has been thought that a protection may be provided by a germicidal action of the gastric juice on the tubercle bacilli. That such proteotion is not afforded by the gastric juice of guinea-pigs has been shown by the experiments of Baumgarten ${ }^{5}$ and of Fischer, ${ }^{6}$ nor by artificially prepared gastric juice by those of Falk." As a matter of fact. we know that primary intestinal tuberculosis does occur in man. Woodhead ${ }^{8}$

2 The Use of Tuberculin for Lessening the Prevalence of Tuberculosis amongst Cattle and Children. 1899. 3 The Animal Tuberculoses, p. 73

4 Milk as an Agency in the Conveyance of Disease, Medical Record. March, 1896.

5 Lehrbuch der Pathologischen Mykologie, 1890, p. 548.

${ }^{6}$ Archiv für Experimentelle Pathologie und Pharmakologie, 1886, Band xx., p. 446.

7 Virchow's Archiv, 1883, Band xciii., p. 177.
8 Medical Press and Circular, 1888, xiv., p. 265. states that he has seen a very large number of cases in which infection seemed to be from the intestine. Cohnheim, Aufrecht, and Peterson ${ }^{9}$ hold the same view. Three cases of evident primary tuberculosis of the intestine have been reported recently; one in an adult by Dr. Hodenpyl, ${ }^{10}$ and cases in infants by Dr. Northrup ${ }^{11}$ and by Dr. J. Lewis Smith and the writer. ${ }^{12}$

\section{Clinicat Evidence of the Transmission of Tuber- CULOSIS BY MitK.}

Clinical evidence of the transmission of tuberculosis by milk is less satisfactory than is that furnished by some other diseases on account of the long duration of the incubation period, the less acute character of this disease, and the varying degree of susceptibility to it found in different individuals. Some cases, however, are reported in which the evidence against the milk is fairly strong. Thus, in a dairy in Scotland ${ }^{13}$ three cows were found to have tuberculous disease of the udder. In the institution to which this milk was supplied the mortality from tuberculosis during the last year was 30 per cent. and during the preceding year 40 per cent. of the total mortality. Brouardel ${ }^{14}$ reported that in a boarding school in which there were 14 girls five contracted tuberculosis from drinking the milk of a tuberculous cow. Ollivier ${ }^{15}$ tells of another boarding school in which milk from a tuberculous cow was used and in which 13 cases of tuberculosis occurred. Dr. Demme ${ }^{16}$ states that in the Children's Hospital at Berne four infants, with no tuberculous ancestry, died from intestinal and mesenteric tuberculosis as the result of being fed upon the unsterilised milk of a tuberculous cow." Kanthack and Sladen ${ }^{17}$ found on examination of the Cambridge milk-supply that more than half the supplies tested-nine out of 16proved infective, while of the 90 guinea-pigs inoculated in the course of the experiments no less than 23 (25.55 per cent.) developed tuberculosis. There is an opinion prevalent in some quarters that the conveyance of tuberculosis by cream is slight as compared with danger of its conveyance in milk. These experiments point in exactly the opposite direction. Three times out of the nine cases in which a positive result was obtained did the cream produce tuberculosis when the sediment failed to do so, and in no single case was the sediment infective when the cream was not equally or more so.

The following facts are taken from Professor Woodhead's ${ }^{9}$ Würzburg Therapeutische Monatshefte, 1891, p. 18.
10 Medical Record, 1895 , vol.

11 Proceedings of the New York Pathological Society, 1890, p. 42. 12 Smith and Freeman: American Medical and Surgical Bulletin, 12 Smith and Freeman: American Metical and Surgical Bulletin

1s Woodhead: Medical Press and Circular, 1888,

15 Bulletin de l'Académie de Médecine, 1891, tome Iv., p. 288. 16 Cornell University Agricultural Experiment Station Bulletin vol. lxv., p. 137 . 17 The Lancet, Jan. 14th, 1899, p. 74 
paper on "Tabes Mesenterica and Pulmonary Tuberculosis":-

From post-mortem examinations at the Royal Hospital for Children in Edinburgh, in 127 cases of tuberculosis in children tubercular ulceration of the intestines were found in 43 instances. It is interesting to notice that the age incidence bet

meningeal lesion corresponds very closely.

\begin{tabular}{|c|c|c|c|c|c|c|c|}
\hline \multicolumn{6}{|c|}{$\rightarrow$} & $\begin{array}{l}\text { Intestinal } \\
\text { tuberculosis. }\end{array}$ & $\begin{array}{l}\text { Tubercular } \\
\text { meningitis. }\end{array}$ \\
\hline \multicolumn{4}{|c|}{ During the first year } & $\ldots$ & $\ldots$ & 1 & 0 \\
\hline 1 to $2 \frac{1}{2}$ & ears & $\ldots$ & $\cdots$ & $\cdots$ & ... & 14 & 15 \\
\hline 3 to $5 \frac{1}{2}$ & $"$ & $\ldots$. & $\ldots$ & $\cdots$ & ... & 10 & 21 \\
\hline 6 to $7 \frac{1}{2}$ & ," & $\ldots$ • & $\ldots$ & $\ldots$ & $\ldots$ & 7 & 8 \\
\hline 8 to 10 & , & ... & ... & ... & ... & 5 & 8 \\
\hline 11 to 15 & $"$ & $\ldots$. & $\cdots$ & $\cdots$ & $\ldots$ & 6 & 2 \\
\hline
\end{tabular}

In 14 out of 100 cases in which the mesenteric glands were affected there was no tubercle found in any other part of the body. In the class from which the patients in the Royal Hospital for Sick Ohildren are drawn the infants during the first year of their life, and sometimes for a longer period, are suckled at the breast. After extremely unsuitable, but it is in by far the larger proportion of cases partially composed of cow's milk. As we have already seen it is after this first year that there is such a rapid rise in the number of cases in which the mesenteric glands are affected. During the first cases in which the mesenteric glands are affected. During the first year, whilst the child is suckled by its mother, it is not nearly so liable to mesenteric tubercle as at a later period. Anyone who has worked at the subject will have been struck by the fact that although tuberculosis in the human subject is so frequently met with in young parried women, tubercular mammitis is extremely rare-so rare, in fact, that Dr. D. Hubermaas ${ }^{18}$ was able to collect and record only some eight cases. In cattle, on the other hand, where the mammary gland carries on its functions under conditions which are far from normal, this tubercular mammitis is not by any means of infrequent occurrence. Albert 19 has on the rejected milk from a tuberculous cow, succumbed to tuberculosis. Numerous other observers-Klebs, ${ }^{20}$ Bollinger, 21 Stein, ${ }^{22}$ Johne, ${ }^{23}$ Martin, 24 Bang, 25 Toussaint,26 and many others besides Koch,27 concur in stating that if milk from cattle with tubercular udders be given for any lengthened period by the mouth (or injected into the peritoneal cavity) tuberculosis will be developed in calves, hens, \&c. ..... Everyone engaged in practice will readily recall the numerous cases in which tubereular disease of bone, of syrovial membranes, \&c., has followed on measles, scarlatina, small-pox, and similar conditions, or in which an attack of typhoid or intestinal mischief or some form had been looked upon as marking the date soon after which serious tubercular mischief was developed. ..... It is of course impossible to bring direct experimental proof to bear in the case of the human subject, but the indirect evidence recently adduced by various continental and home observers, and the examination of series of cases such as those I have brought forward, should be very strong evidence that in children, especially in those who are subject to the wretched hygienic conditions and bad feeding to which unfortunately so many of our porer our poorer class children are exposed, tuberculosis may be

It has been shown above in Professor Woodhead's paper that "Everyone engaged in practice will readily recall the numerous cases in which tubercular disease of bone, of synovial membranes, \&c., hare followed on measles, scarlatina, small-pox, and similar conditions, or in which an attack of typhoid or intestinal mischief of some form had been looked upon as marking the date soon after which .serious tubercular mischief was developed." It is precisely in these cases that a liquid but nourishing diet is required. Milk is at once the most suitable food, and it is prescribed and its use enforced for several weeks or may be months at a time. If, however, this milk be given in the raw state (unless it comes from cows certified to be free from tuberculosis) it is more than probable that at times or continuously it may contain virulent living tubercle bacilli. It does not, then, seem at all extraordinary that some of these patients after being thus infected may succumb to intestinal tuberculosis or to tuberoutosis com menoing in the intestines, but having become generalised is

18 Beiträge zur Klinischen Chirurgie; Mittheilungen aus der Chirurgischen Klinik zu Tủbingen, Band ii., Heft 2

1 Quoted in the Journal of Comparative Medicine and Surgery, January, 1886, p. 93.

Archiv fur Bxperimentelle Pathologie und Pharmakologie, Leipsic, Band 7, p. 31, 1873

21 Ziemssen's Handbook, 1876, and Baier, Aerztl. Int. B1., 1883. 22 Inaugural Dissertation, Berlin, 1884.

23 Fortschritte der Medicin, Band iij, 1885

24 Revue de Médecine, Paris, 10 Fev., 1884

25 Nordiskt Med. Arkiv, Band xvi., and Proceedings of the International Medical Congress, Copenhagen, 1884, vol. i., Pathological Section, p. 11.

26 Comptes Rendus de l'Académie des Sciences, Paris, 1881, tome xcii., pp. 350,741 . 97 Mittheilungen aus dem Kaiserlichen Gesundheitsamte, Band
ai., Berlin, 1884. more manifest in the meninges or the lungs. Thus, in the extract mentioned above, out of the 127 cases in 100 instances the mesenteric glands were affected, and out of these 100 cases only 20 were diagnosed as abdominal tubercle, and this would be considerably reduced were the doubtful diagnoses eliminated. It should be remembered that all who drink tuberculous milk are not susceptible to the disease, and that even some of the infected may recover. The disease in the abdominal, mesenteric, and other glands may become stationary, and the nodules may calcify, just as the disease or nodules do in other parts of the body.

In Denmark whenever an owner of cattle requests that his cattle should be tested with tuberculin without charge to himself, the State demands that certain rules must be conformed to; amongst the more important of these are the following: 1. After the test has been applied the herd is separated into two portions, the sound and the reacting animals; the milk from the reacting animals must not be used as food by man or animals unless it has been boiled or heated to $85^{\circ} \mathrm{C}$. 2. In large dairies, if any of the milk is not used during the day, this milk must be heated to $85^{\circ} \mathrm{O}$. previously to its return to the farms where it may be used for the purpose of feeding animals. 3. On some farms it was found that although there was no tuberculosis amongst the cattle a number of pigs contracted tuberculosis and died from this disease. This led to an investigation when it was found that the heating of the milk returned from the larger dairies was not properly done, and that living virulent tubercle bacilli were found in the returned milk. The law now compels all dairies that return unconsumed milk to heat it to $85^{\circ} \mathrm{O}$.

Professor Bang ${ }^{28}$ states that by a short heating at $85^{\circ} \mathrm{C}$. the tubercle bacilli are killed, and if immediately afterwards the milk be well and rapidly cooled it loses its cooked taste ; establishments which are carrying out this process of "Pasteurisation" are doing a good business in Copenhagen and other large towns. Calves and pigs, when fed on milk, whey, and buttermilk containing living tubercle bacilli, are exposed to the danger of contracting consumption just as is the human subject. Experiments carried out in Denmark, Germany, and other countries, prove conclusively that this source of infection plays an important part in the dissemination of tuberculosis. Fortunately it has been proved that an excellent butter can be made with cream that has been heated to $85^{\circ} \mathrm{C}$. For some years it has been the custom in Denmark to heat cream to $80^{\circ} \mathrm{C}$. and more rarely to $85^{\circ} \mathrm{C}$. before churning. The new law does not absolutely demand this, but we may consider that the law which demands that all buttermilk must be heated to $85^{\circ} \mathrm{C}$. before being returned will as a consequence bring about the practice that almost all the cream will be heated to this temperature, thus removing the difficulty of having to heat the buttermilk separately after churning. In an address given on the occasion of a visit of Suffolk farmers to Copenhagen in June Professor Bang said that in an experiment on five calves that were free from tuberculosis he gave to each of them a feeding of 40 cubic centimetres of milk taken from a tuberculous udder, and repeated this a week later. On post-mortem examination made some time afterwards he found that all five were affected with tuberculosis, the starting point in each case being the intestine. He emphasised this point to show the great importance of maintaining the careful separation of the healthy milk and the tubercle-infected milk so that there may never be a single chance of the milk containing living tubercle bacilli being given to healthy calves.

Cambridge

28 Nordiskt Med. Arkiv, 1899, N:O 22.

Surrey Convalescent Home.-Founder's Day at the Convalescent Home for Surrey Men at Seaford was celebrated on July 27th by a luncheon at the Esplanade Hotel, followed by a reception at the Home. Sir Trevor Lawrence, Bart, the chairman of the committee, said that the income for the year under review was $£ 200$ less than might have been expected. The committee submitted their ninth annual report which showed that 622 patients were admitted to the Home during the year from April 1st, 1900 , to March 31st, 1901. The statement of accounts showed that the total income was $\$ 1657$ and the total expenditure $£ 1792$. 